\title{
Effects of development interventions on biocultural diversity: a case study from the Pamir Mountains
}

\author{
L. Jamila Haider ${ }^{1}$ (D) $\cdot$ Wiebren J. Boonstra ${ }^{1} \cdot$ Anzurat Akobirshoeva $^{2} \cdot$ Maja Schlüter $^{1}$
}

Accepted: 30 November 2019 / Published online: 23 December 2019

(c) The Author(s) 2019

\begin{abstract}
The relationship between nature and culture in biocultural landscapes runs deep, where everyday practices and rituals have coevolved with the environment over millennia. Such tightly intertwined social-ecological systems are, however, often in the world's poorest regions and commonly subject to development interventions which effect biocultural diversity. This paper investigates the social and ecological implications of an introduced wheat seed in the Pamir Mountains. We examine contrasting responses to the intervention through participatory observation of food practices around a New Year ritual, and interviews in two communities. Our results show how one community fostered biocultural diversity, while the other did not, resulting in divergent processes of social and cultural change. In the former, ritual is practiced with traditional seed varieties, involving reciprocal exchange and is characterised by little outmigration of youth. In contrast, the second community celebrates the ritual with replaced store-bought ingredients, no longer cultivates any grain crops and where circular migration to Russia is the main livelihood strategy. Coevolution as an analytical lens enables us to understand these divergent pathways as processes of dynamically changing social-ecological relations. The paper suggests that a deeper understanding of socialecological relationships in landscapes offers a dynamic and process-oriented understanding of development interventions and can help identify endogenous responses to local, regional and global change—-thereby empowering more appropriate and effective development pathways.
\end{abstract}

Keywords Biocultural diversity $\cdot$ Coevolution $\cdot$ Development $\cdot$ Everyday practice $\cdot$ Pamir Mountains $\cdot$ Resilience $\cdot$ Ritual

\section{Introduction}

Every landscape on Earth is influenced to some degree by people, and in turn, societies and cultures are shaped by landscapes. Agricultural landscapes in particular are visibly shaped by human practices: wild varieties of seeds are domesticated, infertile lands are tended, irrigated, and fertilised to create life-giving soil, certain seeds are saved while others are abandoned, and so on.

Electronic supplementary material The online version of this article (https://doi.org/10.1007/s10460-019-10005-8) contains supplementary material, which is available to authorised users.

L. Jamila Haider

jamila.haider@su.se

1 Stockholm Resilience Centre, Stockholm University, Kräftriket 2B, 10691 Stockholm, Sweden

2 Pamir Biological Institution, 1 Kholdorova str., Khorog, GBAO, Tajikistan
These coevolving relationships between nature and people, between ecosystems and society, are often difficult to see or even to articulate, which in turn makes them difficult to understand and care for. Common ways these relationships have been articulated include: dwelling (Ingold 1993); social-ecological systems (Folke 2006; Folke et al. 2016) or coupled human and natural systems (Kramer et al. 2017). It is also widely accepted that human well-being and biophysical processes are intricately connected (Raworth 2017). Within sustainability research, relationships between people and their environment tend to be deconstructed into separate social or ecological entities, and the researcher or development practitioner's challenge becomes to re-connect different component parts into integrated frameworks or programmes (in the concepts of 'ecosystem services' or 'Nature's contributions to people' for example Díaz et al. 2018).

The limitations and consequences of such dichotomous and unidirectional concepts, and subsequent analyses or interventions, become particularly apparent and problematic 
in deeply intertwined biocultural landscapes. Narrow development or conservation interventions in such landscapes may perpetuate or exacerbate the problems they are designed to solve (Fischer and Hajdu 2015; Lade et al. 2017). How to address poverty and increase human wellbeing without eroding biological and cultural diversity remains a major development and conservation challenge.

The paper aims to address this challenge through improving our understanding of the effects of development interventions on the coevolution of biocultural landscapes, as expressed through changes in daily practice and ritual. We investigate the introduction of an 'improved seed" ${ }^{1}$ in the Pamir Mountains of Tajikistan, a biocultural landscape where human practices and the environment have coevolved over millennia. We ask two main questions: (1) what factors gave rise to the intervention (the introduction of the seed), and its subsequent failure, and (2) what were the effects of the intervention on coevolved social-ecological relationships, as manifested in changes of, and represented by, people's everyday practices. In observing everyday practice and ritual we aim to overcome some of the limitations of binary conceptualisations of nature and culture. Our results compare responses to the introduced seed across two communities. The paper concludes with practical and theoretical insights on how to re-think development interventions to better consider biocultural diversity.

\section{Theories of modernist intervention and coevolution}

The introduction of new seeds and corresponding agrochemicals is typical of modernist style interventions (Wanjala and Muradian 2013; Scott 1998; Li 2007). Such interventions often fail to account for the social-ecological complexity and diversity of rural livelihoods and fail to perceive the high degree of uncertainty that surrounds interventions in these conditions (Mosse 1998; Acheson 2006). Richard Norgaard (1994) argues that modernist interventions decouple social-ecological interactions which distorts their coevolutionary dynamics, in turn perpetuating dependence on modernist technologies. As a counter-narrative to development as modernisation, Norgaard proposes development as the coevolution between social and ecological systems, further specifiying that cultural and biological diversity are central to sustainable development (Norgaard 1994, p. 178). Norgaard proposes a coevolutionary framework (between five elements: values, organisation, technologies, environment and knowledge) as both an alternative paradigm of

\footnotetext{
${ }_{1}$ A seed developed outside of the local context, selected for specific characteristics such as productivity or pest resistance. In this case the introduced seed is not Hybrid which is why we refer to 'improved' as is stated in the local context.
}

development, and as an analytical framework for understanding development processes. While the intent of the former aligns with the aims of this paper, it is the latter analytical function, which we apply in this paper.

We selected coevolution theory as an analytical framing to understand dynamic relationships between social and ecological processes. Bruno Latour famously argued that modernity has created an artifical dualist distinction between nature and society (Latour 1993). Post-modernism and poststructuralism have long challenged cultural essentialism and biological reductionism (Sayer 1997), but despite theoretical advances in this thinking in the social sphere, frameworks analyzing social-ecological relationships in more processoriented or relational ways remain nascent (Mancilla Garcia et al. 2019). Increasingly there is a process-relational turn to understanding social-ecological relationships (West et al. 2018; Mancilla Garcia et al. 2019). This paper situates itself in this endeavour. Coevolution as an analytical framwork: (i) offers an opportunity to view social and ecological processes as co-constituted, and (ii) is embeded in a language of progress and development relevant to the processes we study in this paper (Norgaard 1994).

Coevolution is a core-underlying tenant in the study of complex social-ecological systems and resilience (Folke 2006). Recent research has synthesised insights from cultural coevolutionary theory in relation to resilience theory, claiming they are compatible fields to improve understanding of human responses and adaptations to cross-scale change (Reyes-García et al. 2016). In cultural coevolutionary theory, mechanisms that cause cultural change are located in the everyday lives of individuals (Richerson and Boyd 2005). Lived experience and everyday practice have been recently recognised as sources of resilience for development and adaptation to environmental change (Tidball et al. 2016; Brown 2016), have been observed as a form of resistance against patriarchy (Hegland 1995), the state (Scott 1998) or as pockets of social-ecological memory (Peloquin and Berkes 2009; Berkes et al. 2002). In this paper we integrate these various strands of coevolutionary thinking to advance the operationalisation of Norgaard's coevolutionary framework- which has thus far remained underdeveloped in application to sustainability problems (Kallis 2007).

\section{Agri-cultural practices in the biocultural landscape of the Pamir Mountains}

The Pamir Mountain region provides an instructive case study. The area is rich in biocultural diversity. In one of the world's highest mountain ranges, over millennia people have created fertile niches in narrow valleys where they domesticated crops and created an abundant diversity of grains, pulses, nuts and fruits (Vavilov 1917; Nabhan 2009). 
Vocabulary has coevolved with seeds (as well as many other aspects of nature and society), giving rise to different unwritten languages in every valley and a celebrated mountain culture (Middleton 2016). The biocultural diversity of the Pamirs plays a crucial role in local resilience to social and ecological change, but is also of global significance as a repository of agricultural biodiversity and social and ecological memory. For example, over 150 varieties of wheat grow in the Pamirs, each with different biophysical properties and cultural uses, with each requiring distinct practices to maintain them (Van Oudenhoven and Haider 2015). ${ }^{2}$ One particularly famous and celebrated wheat is a red wheat, called Rashtak (or Rush-kakht), which is used in the most important ritual of the year, Baht-ayom, to mark the waning of winter and to celebrate the arrival of Spring during Nawruz, the Persian New Year.

Contrary to its biological and cultural richness, the Pamir region remains the poorest area of Central Asia and of all post-Soviet states (Markandya and Sharma 2004; Robinson 2005; Middleton 2016). Despite high literacy rates (99\%) (Middleton 2016), very few job opportunities exist, and when they do, salaries are often not enough to provide for a basic level of subsistence. ${ }^{3}$ With little opportunity to stay on the land, many young Pamiri people leave in search of work in Russia or other Central Asian states. Even more so than in the rest of Tajikistan, ${ }^{4}$ the people in the Pamirs depend heavily on remittances. The region suffered following the collapse of the Soviet Union and ensuing civil war, and has been subject to major aid efforts, with a primary goal of increasing agricultural productivity (Middleton 2016). As elsewhere, the introduction of modern farming technologies has however often led to an erosion of agricultural biodiversity (McAllister 1992; Wiggins and Cromwell 1995; Jacobson 2013; Lade et al. 2017). To understand the effects of interventions and ensuing cultural change, we focus on observing specific practices related to the ritual Baht-ayom in Bartang valley in Tajikistan.

\footnotetext{
${ }^{2}$ Research during the Soviet Era led by Nikolai Vavilov recorded 273 varieties of wheat in Central Asia and 151 of these in the Pamir Mountains. The diversity of grains emerges from a combination of niche microclimates across strong altitudinal gradients, adaptive mutation through UV radiation, and extreme daily temperature ranges (interview P1). The selection of the fittest grains however, is not due only to the environmental conditions, but to generations of farmers selecting seeds year after year whilst passing on knowledge on how to cultivate them.

3 The average monthly wage for the agrarian sector in Tajikistan was below 60 USD in 2014 (Asia-Plus 2014).

4 Tajikistan is the most remittance dependent nation in the world, with over 50 percent of its GDP coming from remittances (World Bank, Migration and Remittances Team 2014).
}

\section{The coevolution of Baht}

In the Pamirs, the year begins and ends with Baht-ayom to celebrate the coming of new and the passing of the old. Nawruz in the Pamirs is celebrated according to a traditional calendar, closely connected to changes in the landscape as experienced by the human body (Kassam et al. 2011; Oudenhoven and Haider 2015). Preparations for Nawruz begin at solstice and when elders feel the sun reaches the knee in the body (approximately 20 days later), Baht-ayom is celebrated.

Baht is a sweet festive porridge from which Baht-ayom has its name. The best Baht of the Pamirs is said to come from Bartang valley, because it is made with Rashtak. Rashtak was domesticated hundreds of years ago presumably for its robustness to a short growing season and poor soils at high altitudes, but also because of its unique and beloved nutty and sweet flavour. Over centuries people created soil for Rashtak to grow, and dug vertiginous irrigation channels to bring water to the seeds. As the seeds took root, so too did practices and norms, and a diverse vocabulary to describe them and the conditions in which they grow. Selected for its unique properties, Rashtak was celebrated over centuries through cultural and spiritual rituals. It is difficult now to disentangle whether the culture expressed so distinctly through ritual and daily practice exists because of the seed or if the seed exists to serve these cultural practices. Culture and nature have become inextricably intertwined.

The story of Baht shows how biological, cultural and linguistic diversity coevolved, and are interrelated within a complex social-ecological adaptive system (Smith 2001; Harmon 2002; Maffi 2005). The high mountain valleys of the Pamirs have remained relatively isolated enclaves, and could be considered as refuges of biocultural diversityareas that store and transmit social and ecological memory (Barthel et al. 2013; Chan et al. 2016). It would be a mistake however, to view the mountains as isolated or forgotten. As an artery of the Silk Road, the battle ground of British and Russian empires during the Great Game of the late nineteenth century, and a strategic outpost of the Soviet Union, the Pamir Mountains have been both subject to, and part of, sweeping social and environmental changes over centuries.

\section{Introduction of improved wheat varieties to the Pamir Mountains}

The combination of the collapse of the Soviet Union (and agricultural subsidies) and ensuing Tajik civil war led to an abrupt end of Soviet imports and began the so-called "starvation time." People returned to their lands from factories or from their jobs as labourers in cotton fields, fodder crops were swapped for grain, and wheat production increased from 3000 ha during Soviet times to 10,000 ha during the civil war in an attempt to cover the gap in basic provisions 
(interview P1). The Pamirs were completely closed-off to the outside world, and only aid organisations were allowed to enter to deliver humanitarian aid. Following the collapse of the Soviet Union, development agencies took over the role of the former Soviet government in providing basic goods and services, first and foremost through humanitarian aid. To illustrate this point, although 25 years have passed, most people still refer to the main non-government development organisation (NGO) in the area as Hazina, the name of the former Soviet shops, which were centralised providers of all basic goods. Multiple 'improved' seed varieties were introduced between 1994 and 1997 with the motivation to increase agricultural production. Two of the introduced seeds holding a prominent place in collective Pamiri memory are commonly known as Mahmoudi and Atoi ${ }^{5}$ both common bread wheat varieties (Triticum aestivum/vulgare).

\section{Methods and procedures}

\section{Case study in the Pamir Mountains}

This study is situated in the context of a longer-term research engagement and commitment to the Pamir region (since 2009, as recorded in Haider and Van Oudenhoven 2018). The case presented in this paper was selected based on interviews with the main NGO in the Pamirs who highlighted the introduction of the improved wheat varieties as a typical agricultural development intervention in the 1990s.

Seeds remained a source and symbol of resilience in the Pamirs throughout the Soviet era despite grain production falling drastically. In the 1960s, the collective Sovhoz farms were organised to almost exclusively produce fodder, since wheat and other grains could be imported from higher yielding areas of the Union. People were also forcefully removed from their land to other parts of Tajikistan to labour on Sovhoz collective farms. Nevertheless, many of the wheat varieties survived through both in-situ and ex-situ conservation. Rashtak survived as a valued ritualistic crop which farmers continued to grow for their personal use.

To study the effects of intervention on biocultural diversity we focus on the introduction of Mahmoudi and Atoi seeds. The general failure of high-input seed interventions in terms of sustainability, as well as resilience and equity, has been well documented (McAllister 1992; Wiggins and Cromwell 1995; Jacobson 2013), which is why we use it here to exemplify a modernist intervention (Scott 1998). We use a single embedded case study methodology (Yin 2003), where the introduction of and response to the seeds are the 'case.' Within this case we selected two units of analysis

\footnotetext{
$\overline{5}$ Some people call Atoi,'Turki' based on place of origin in Turkey.
}

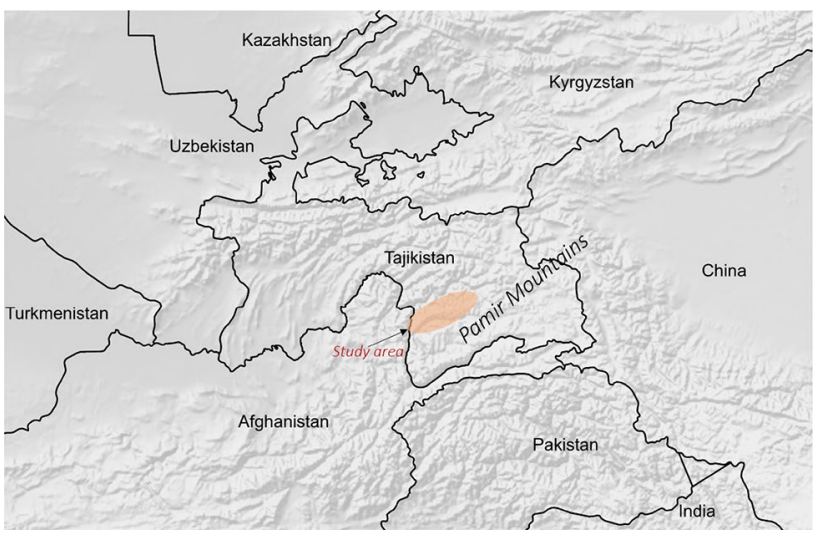

Fig. 1 Map of Pamirs and surrounding countries with study area demarcated. Source Public domain https://www.naturalearthdata.com

(villages) using a process of casing. The purpose of selecting two cases is not to conduct a comparative study, since the scope conditions of the two communities vary (Cohen 1989) — but rather to record two different development experiences and the variable effects of the introduced seeds and responses within different contexts. Our use of ritual is both formal and ceremonial (and plays a role in manifesting values) as used in the athropological tradition, but also overlaps with the broader microsociological use of the term as a social situation producing a 'momentarily shared reality, which thereby generates solidarity and symbols of group membership' (Collins 2004). Through this understanding of ritual, Baht-ayom, creates a shared social situation within communities. This is not to dismiss the importance of social differentiation within communities, but rather that we create an opportunity to compare differential effects of the same intervention between communities: one in which the ritual is still practiced with the traditional seed variety, and another community in which the ritual is practiced with replaced products.

The two communities studied are situated in Bartang valley (administrative district Rushan, see Fig. 1). Bar means width, and - tang narrow: an astute description of the most remote valley of the Pamirs. It is also the poorest valley of the Pamirs and well known for its strong and vibrant traditions, rituals, and folklore. More than half the families in Tajikistan have family members working abroad (Danzer et al. 2013), making it the most remittance-dependent nation in the world (over 50\% of the GDP is made up of remittances (World Bank, Migration and Remittances Team 2014).

Village A, is situated away from the main road, and lies above $3000 \mathrm{~m}$ asl. The 64 households, situated across five neighbourhoods (tabaks), do not have mobile phone connectivity or electricity. Soviet-era gas lamps are the only source of light in the long winter evenings along with the fires that warm the hearth (khitsor). The recently constructed 
precipitous and narrow road is often blocked with landslides or avalanches. The main occupation in Village $\mathrm{A}$ is farming 45 ha of land, of which between 22 and 24 ha are under wheat cultivation, including Rashtak. Less than 10 percent of young people are abroad. Major development priorities include improving the road and irrigating an orchard. Village A has a primary school, but no medical centre, and no shops.

The second community, Village B was selected based on previous observations of rituals that maintain connections to the landscape, such as the continued celebration of Bahtayom (Van Oudenhoven and Haider 2015), despite a complete shift from grain cultivation to fodder. Village B has a primary and high school, a handful of small shops selling basic food items, and a medical centre. Village B is comprised of four different tabaks. The main source of income is remittances, with almost all young people working abroad. Development priorities include building a boarding school.

Taken together, these two communities represent different development trajectories of rural life in the Pamirs. Village B, situated in the valley, no longer grows Rashtak, or any grain staples, and imports almost all its food. For Bahtayom, Village B still receives Rashtak from Village A, which is more isolated and still maintains many traditional varieties of grains and a high diversity of landrace seeds.

\section{Data collection}

The primary method of data collection was participatory observation of daily practices, since meaning and tacit knowledge are difficult to articulate through spoken word, and can be better observed than heard (Slutskaya et al. 2012). Our participation as authors in these practices ranged from moderate to active participation Slutskaya et al. 2012, p. 58), with over 7 years of regular engagement with communities in the Pamirs, and one of the authors is from the Rushan district with Rushani language (Bartangi is a dialect of Rushani) as mother tongue, and has conducted ethnobotanic research in Bartang valley for more than a decade. The period of fieldwork for this specific data collection took place April-July 2016.

We used food preparation as a social situation (Spradley 1980 , p. 39) to increase our ability for active participant observation. Preparing food together (researchers and participants) helps break down conventional power relations. In a context where a woman's views are often subordinate, through preparing food she becomes the expert not just of food preparation, but also of land-use, post-harvest processes and cultural rituals. Moreover, talking about food is emotive and evocative and has the potential to excavate ideas that are otherwise oppressed (Haider and van Oudenhoven 2018). During our stays in the two communities we asked different groups of people (usually within the natural configuration of local tabaks) to prepare traditional recipes using Rashtak (or in Village B, using imported flour). We participated in collecting the ingredients from storage, firing up the tandoor, preparing the food, and finally eating together. At times, we spent entire days in the kitchen, and other times we walked through fields, spent time at the mill, or visited spiritual places connected to the food. In this way, food becomes a tangible way to understand changes over time, and elicits traditional ecological knowledge from actors who otherwise do not feel they have much of a voice (Haider and van Oudenhoven 2018).

In addition to participatory observation, semi-structured interviews were conducted with informants in both communities and the main local non-governmental organisation. In total, 53 interviews were conducted during the fieldwork period for various different research questions, with 17 interviews used for analysis in this paper. Due to the inductive nature of the observation and interview process, all interviews related to the seed intervention were included (See Supplementary Material Appendix A). Four interviews were used from NGO staff, and one from a local agronomist. The two villages were selected due to the impact of improved seeds on these villages, where we pursued snowball and opportunistic sampling following from the group food preparation activity. In total, six interviews each were done in Village A and Village B with an even distribution of gender (See Supplementary Material Appendix A). Interviews were conducted in Rushani/Bartangi and translated to English through simultaneous translation by the Pamiri author. Interviews were transcribed and coded using atlas. $t i$. Local Bartangi words are used throughout the text to describe crop varieties, since they are endemic to this area and specification of varieties is often done in the local vernacular. Prior consent was received for all data collection; photos and names reproduced with permission.

\section{Analysis}

In order to uncover motivations, effects and responses to the seed intervention, an abductive coding approach was used, in which we worked through iterative cycles of inductive and deductive coding (Miles and Huberman 1994, p. 65; Lofland and Lofland 2006; Swedberg 2017). In the first round, we coded descriptive aspects of the data, including in-vivo codes around the research questions. A second round of coding used the coevolutionary framework (Norgaard 1994) to code the broad categories of Environment, Values, Knowledge, Organisation and Technology. To our knowledge this is the first time the framework was used on empirical data in this way. In the third round, we coded the relations between nodes of the coevolutionary framework. The analysis centred around the ritual of Baht-ayom and everyday practices involving Baht to operationalise the various components and relations of the theoretical framework. 
To do this, we break down the ritual into a set of practices: (i) sowing (seed), (ii) harvesting (grain) and (iii) celebration (using flour). The relations between nodes are articulated as biocultural practices which are ultimately what was coded (See Supplementary Material Appendix B), enabling a novel relational approach which focuses the analysis on relationships rather than entities.

\section{Results}

\section{The introduction and demise of Mahmoudi and Atoi seeds}

The high-input intervention style of improved seed varieties, fertilizers and other agro-chemicals that were introduced to the Pamirs by development agencies were intended to make up for the loss of Soviet inputs (Lerman et al. 2003) and are typical of disaster relief interventions (Scoones and Thompson 2011). The following quote from the NGO describes the intentions behind introducing Mahmoudi and Atoi:

We knew it [the introduction of Mahmoudi] would fail on the level of sustainability. But this is what was needed in a time of emergency, of humanitarian crisis. The goal was food security, and we achieved this, which also provided confidence from people and the government to trust us. There were a lot of plusses in this early stage of development (Interview N1).

The seeds were introduced in the mid-1990s to address a period of crisis (famine as a result of the civil war). However, their introduction was shrouded by conflict. An official from the main NGO implementing the seed introduction programme at the time recalls:

I remember that I had huge debates with that scientist at PBI [Pamir Biological Institute] at the time. I was head at the time, and pushed to have these seeds brought in. Mahmoudi, but also Atoi. It was so beautiful. The harvest was so high! In Porchinev [village], 4.5 tons per ha. The local seed, it was 2 or 2.5 tons/ha. But then after 2 years the hybrid ${ }^{6}$ seed turned to zero. I remember all the debate at this time. People telling me that this is wrong, that things are not good, hybrid is not good. But that was my agenda: I need to feed the people. I need 4.5 tonnes ha. People were starving, I don't care about your old seeds and seedbanks, keep it for yourself but give me the opportunity to help you

\footnotetext{
${ }^{6}$ The Mahmoudi seed is often referred to as hybrid, but scientists as Pamir Biological Institute claim it was simply an introduced variety with higher yield expectations.
}

grow more. I had to feed them. I had the opportunity to get them fertilizer and seeds (Interview N2).

On the other side of this debate, the scientist at PBI says he did not believe that the improved varieties of seed could produce higher yields, and says it was distributed despite being susceptible to disease.

When I went to go check on the 7 ha [trial plot of Mahmoudi seed], I saw the wheat had a disease: black rust. Mahmoud brought the rust. Mahmoudi had the disease and they still distributed it everywhere. They put it in the lorry and distributed to all (Interview P1).

Both the seeds and fertilizers were widely distributed for free in 1994. For a few seasons Mahmoudi and Atoi grew well, and people recall high yields. After the second season however, the limitations of this seed became more apparent and a well-known poem in the Pamirs goes: "Khisht Kardam Atoi, adjab kar atoi, pagam ..." which can be translated from Tajik as: "Today we grow Atoi, we made a mistake, tomorrow we must go begging" (Interview N3).

The reasons for the failure of Mahmoudi and Atoi are manifold. As the PBI wheat expert claims, the seed was plagued with disease. Farmers recall that the improved varieties had very small awns on the seedhead, which made them susceptible to being eaten by birds before harvest. During harvest, the grains rotted when left to dry on the fields in the traditional way, and would have required machine harvesting which is impossible on the steep slopes and narrow fields of the Pamirs. As a 'combined mountain agriculture' system (Kreutzmann 2017), most Pamiri farmers practice agricultural as well as pastoral livelihoods. As such, farmers prefer grains with a long stalk that provide both food for human consumption as well as fodder for livestock feed. The new varieties were short, and farmers struggled to cope with the reduction of grain stalks as a fodder source (Interview N4). Moreover, the improved varieties required external fertilizers, which farmers could not afford after the initial free distribution ran out. Perhaps most importantly, the improved seeds could not be saved, and needed to be replaced year after year; a practice foreign to the traditional sharing and barter economy of the Pamirs, and even the collective farming practices of the Soviet regime.

\section{The effects of the intervention on changing practices}

The effects of the introduced seeds on the ritual of Baht and biocultural diversity varied among different communities. While Village A maintained its traditional seeds (including Rashtak) throughout and after the intervention, Village B lost them. In Bartang valley, valley-dwelling villages (like Village B) retrieved lost varieties from relatives in more 
Table 1 Changing practices of the ritual Baht-ayom in Villages A and B

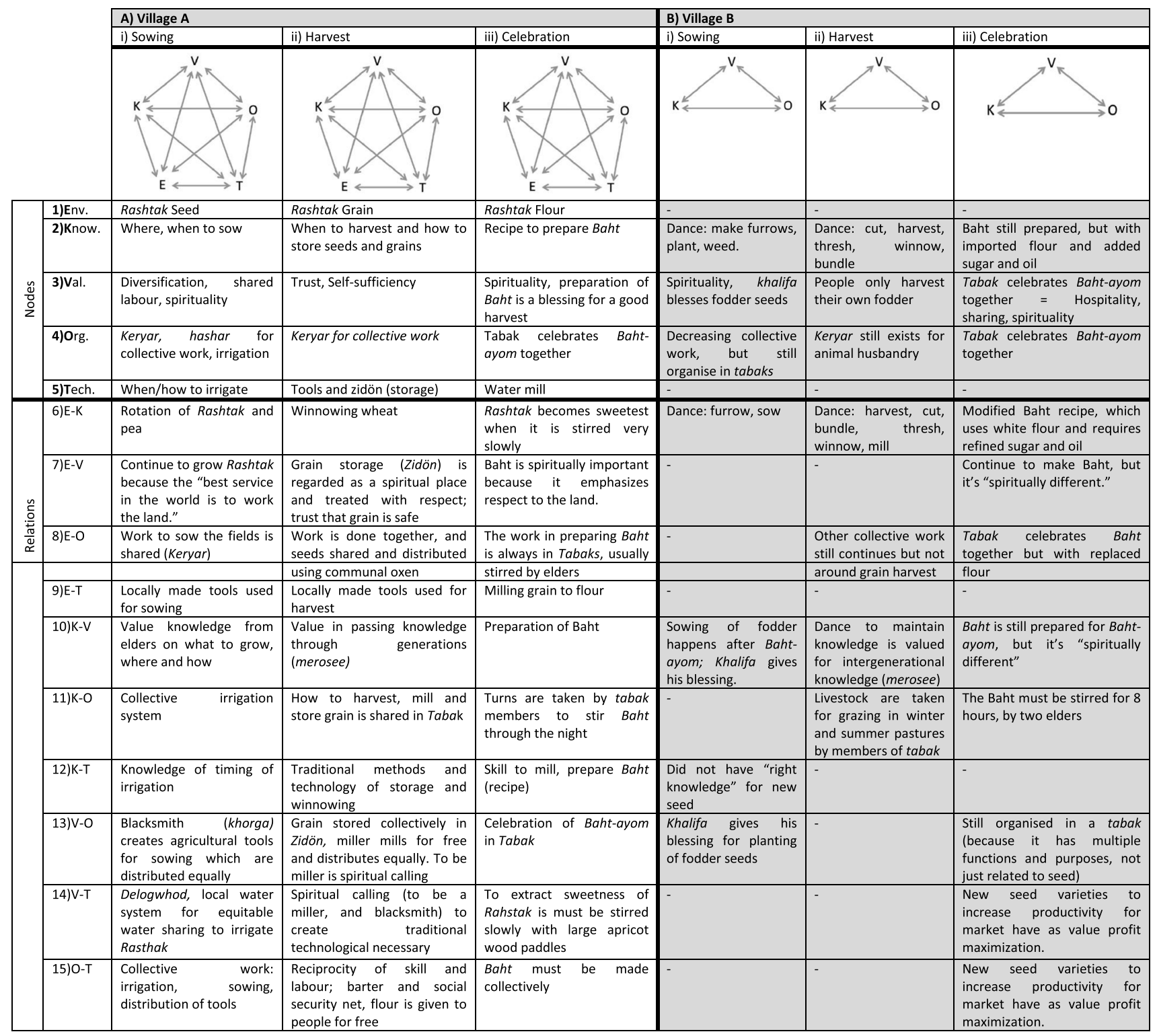

Shaded cell $=$ Replaced traditional practices

Empty nodes $(-)=$ No practice observed

Empty nodes $(-)=$ No practice observed

Baht: porridge made from Rashtak, Baht-ayom: ritual to celebrate the coming of Spring, Delogwhod: equitable water sharing, Keryar: general collective work, Khalifa: religious leader of village, Khorga: a spiritual calling to be blacksmith, Hashar: collective work to maintain canals, Merosee: transfer between generations, Rashtak: red wheat, Tabak: neighbourhood in village, Zidön: traditional grain storage

remote villages (like Village A) who only tried the introduced seeds on a limited amount of land, whilst still cultivating traditional varieties. Respondents were unclear about the history of when precisely Rashtak disappeared and reappeared but in Village B in the late 1990s a few elders reseeded Rashtak. In the following section, changing practices in response to the seed introduction are represented through the three sets of practices that together comprise the ritual as introduced above: sowing, harvesting and celebration. We present and analyse these changes from introduction of the introduced seeds (Technologies) on Rashtak (Environment) as a reconfiguration of coevolutionary relationships between Environment (E), Values (V), Knowledge (K), Organisation (O) and Technologies (T) using Norgaard's framework. 
Table 1 presents the main results of our inquiry with regards to these observed changes. More detailed examples of quotations that guided the content of Table 1 can be found in Supplementary Material Appendix B.

\section{Village $\mathrm{A}$-the Pamirs as a coevolving biocultural system}

The remoteness and altitude of Village A made the adoption of the improved seeds more difficult than for the lower lying communities. Farmers tried the improved seeds but they required fertilisers which they did not have. Fertiliser was initially provided by the NGO, but did not work well because of the steepness of most of the fields and subsequent surface run-off. Farmers in Village A also did not give up the cultivation of their traditional varieties in part because these are "seeds from our ancestors" and farmers describe a deep respect for, and sense of responsibility to conserve traditional varieties. In this manner, Village A can be viewed as a biocultural refuge, and therefore useful as a reference point for a tightly-coupled biocultural system, which is how much of the Bartang valley would have looked in the late 1990s (see Table 1A)

Approximately 20 days before Nawruz, the Rashtak seed (E) which has been set aside to sow (Table 1, column Ai) is taken from the zidön (traditional stilted grain storage) and neighbours gather at an elder's house for keryar (collective work) to prepare the lands and sow the seeds (E-O). The Khalifa (local religious leader) blesses the seeds and the land with a prayer. A farmer in Village A explained the importance of this prayer because:

We have a lot of respect for the land. We need to say nice things to the land and respect it, otherwise we won't get good yield. Our ancestors said that if you say bad things to the land it won't provide good yield (E-V) (Interview VA1).

Oxen plough the fields with harnesses and tools made by the local blacksmith (V-O). In Village A, Rashtak is rotated with makh (Pisum sativum $L$. or the common pea) for nutrient cycling (E-K). "Our local varieties are the most beautiful. We rotate lands with makh and wheat so that the nutrients can be given back to the soil" (Interview VA1). A few weeks later, everyone will come together again for hashar (communal irrigation) to clear the channels and set up the irrigation system (Delogwhod), a system for equal water-sharing (V-T, O-T). Farmers say they continue to grow Rashtak because "Betereen khizmat ... kori deqoni buwad," translated as the "best service in the world is to work the land" (E-V) (Interview VA4).

Rashtak ripens early for an early harvest (Table 1 , column Aii) and is therefore a favoured seed in higher and harsh climates (E-K). The grains are harvested using scythes made by the local blacksmith, khorga (E-T), and left to dry on the field. Once dried, the harvest keryar (collective work) begins and the stalks are threshed by communally owned oxen, and de-husked and winnowed using the tools kalbez and galberr. A schedule is set up to bring the grains to the mill and the rest is stored in the zidön $(\mathrm{E}-\mathrm{V})$ which is situated beside the holy shrine. Various respondents said that the khorga, the blacksmith, was the best thing about Village A because it helped to make them more self-sufficient. To be a khorga is a spiritual calling (V-T) and the knowledge is passed through generations $(\mathrm{K}-\mathrm{V})$. People say it is merosee (hereditary) and the current blacksmith who took over from his father, who had taken over from his grandfather, hopes that his sons will continue (Interview VA6). Tools are not sold, but are given or traded for other goods (O-T).

The blacksmith in Village A is also the miller. Rasthak grains which have been set aside for Baht-ayom (Table 1, column Aiii) are taken from the zidön and taken to him to be milled on a special setting (more space between the millstones) which can better grind the soft, sticky grain (K-T). For Baht-ayom, the celebration of the second day of Nawruz, elders slowly stir a mixture of Rashtak flour and water over a single low fire through the night (E-O, K-O), adding shaved ice to the simmering porridge, to symbolize the end of winter and the coming of spring. The porridge must be stirred slowly to release the characteristic sweetness of the Rashtak seed (E-K). As a farmer in Village A explained: "Baht is very important for us spiritually, to prepare it gives respect to the land. The taste of Rashtak is the most delicious for Baht" (E-V) (Interview VA1). Some Baht is saved to decorate Nasrak, bread animals, which children bring to mountain caves the following day as offerings in prayer for fertility for the coming agricultural season.

The introduction of the seeds did not have a visible effect on the existing relations between seeds, culture or language and the traditional seeds in Village A. Farmers tried some of the introduced seeds in some lower-lying areas of the village, but when they failed, returned to their traditional crops. Respect for ancestry, and traditional knowledge played a big part in the maintenance of traditional seeds: that these seeds were created by ancestors over hundreds of years and are recognised as seeds that can resist natural disasters and different weather events. The situation is changing, however. Village $\mathrm{A}$ is one of the poorest communities in the Pamirs and is food insecure, and like maany other. Villages, dependent on food aid from the World Food Programme and Red Cross, according to whom, local regional production accounts for only 30 percent of basic caloric needs. Since the road opened in 2015 they have stopped growing millet and barley. They receive white flour either as humanitarian aid (each family receives $50 \mathrm{~kg}$ bag per season), or they buy it from valleylying shops. Many valley dwelling villages also receive food aid. Village A continues growing Rashtak mostly because of its spiritual importance. Young people in Village A still 


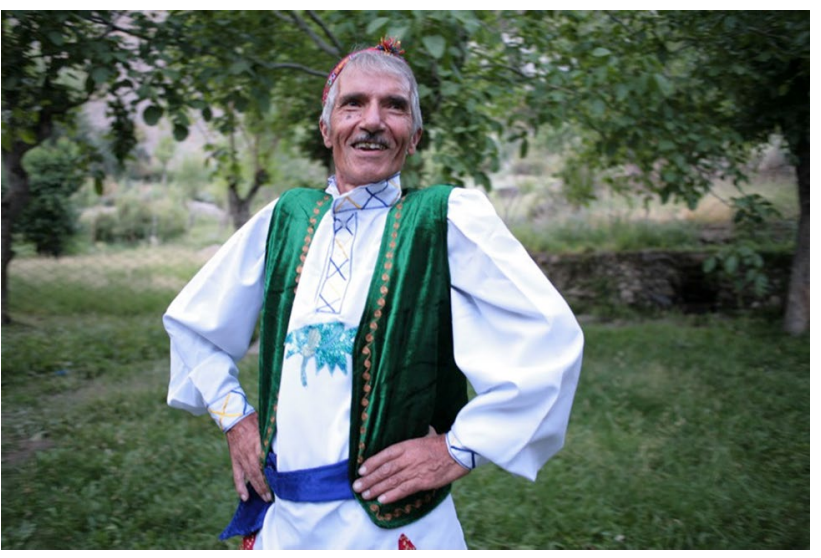

Fig. 2 Harvest dance performed by Sarkori Dawlatmamadov. With permission Photo: Judith Quax

largely work in agriculture and also take over professions from their parents and grandparents (such as the blacksmith and miller). The knowledge and management systems of irrigation continue to exist, as does communal work. In a visioning exercise done as part of a separate study, community members from Village A envisioned a future where their shared values of hospitality and sharing were still at the core of community life and activities, but opportunities for alternative livelhoods, renewable energy production and better infrastructure also featured (see Fig. 4).

\section{Village B-“...spiritually it is not that Baht"}

Before and even through Soviet times, farmers in Village B also grew Rashtak, but land-use today is dominated by fodder production (Alfalfa (Medicago sativa) and Esparcet (Onobrychis sibirica)) and kitchen gardens and grains are no longer sown (Table 1, Column B). Mahmoudi and Atoi were introduced to Village B as a new seed technology (T) and sowed by many farmers (Table 1, Column Bi).

We thought it was an improved seed, it gave better yield than [the] local one, and so we took Mahmoudi and over three years it decreased and decreased and by that time we lost it and the local seed, both (VB4).

An NGO official said that the famers did not have the "right knowledge" for sowing the new seed (K-T) (Interview N4). Since then, Village B has shifted from a subsistence agricultural system to a system of minimal land-use (growing only fodder crops) in order to keep a few small livestock (goats) per family. Despite not sowing grain (Table 1, column Bi), the khalifa (religious leader) still gathers many members of the community during Nawruz to announce when it will be time to sow fodder seed and bless the land for fertility with a prayer $(\mathrm{K}-\mathrm{V} ; \mathrm{V}-\mathrm{O})$. A local schoolteacher is worried about the knowledge that young people are losing, and started to celebrate Taomhoi Meli or 'national foods day' where children ask their parents and grandparents for their favourite recipes and prepare them together, including Baht. Another teacher has choreographed an entirely new dance to help maintain the traditional knowledge (Fig. 2; E-K):

The role of dance is that people should not forget their traditions. They should understand the purpose of weeding, harvesting, cooking. This is the dance for working the land. Start by making furrows, then planting the seeds, then weeding... (Interview VB4).

The dancer continues (Table 1, column Bii), explaining every movement for harvesting grain $(\mathrm{E}-\mathrm{K})$ :

... the cutting, the bundling, and threshing, winnowing, and gathering into sachets. Then the girls hold the bags open and the boys pour the seeds in the bags, and pick up the bags and take it to the zidön. They will take this grain to make flour and bring it to the mill (Interview VB4).

The knowledge of how to cultivate Rashtak for Baht continues to exist in part due to this dance. Nobody harvests grain anymore since it is not economical: flour for the year can be bought from one-month's worth of remittances sent home from Moscow. Besides the remittances, only the harvest of fodder remains, which is done mostly in family units, and fed to livestock which are kept in corrals managed by tabaks. Livestock are brought to pasture on rotation within the tabak structure (K-O), which they use for daily milk and occasional meat when it can be afforded. Baht-ayom is still celebrated in Village B (Table 1, column Biii), despite Rashtak no longer being grown (E-V).

Now we keep the tradition and prepare baht from flour from the shop. The taste is not the same, there are different properties. Physically we keep it, but spiritually it is not that baht (Interview VB4).

The recipe for Baht has been modified, to include oil and sugar to make up for the poorer taste of imported flour (E-K). In this way, baht and other recipes continue to be celebrated, either at the school or in the communal tabaks. The communal structure of the tabaks remains very impor$\operatorname{tant}(\mathrm{V}-\mathrm{O})$.

The people within these tabaks naturally become close friends/almost family. Since you see them every day, multiple times a day for various chores. The structure is from ancient times, and it should be like this. I don't know what I would do without the tabaks. We must do everything we can to preserve this system (VB1).

The coevolutionary relationships in Village B (Fig. 3a) demonstrate how despite the disappearance of sowing and harvesting of Rashtak, the celebration of Baht-ayom maintains 


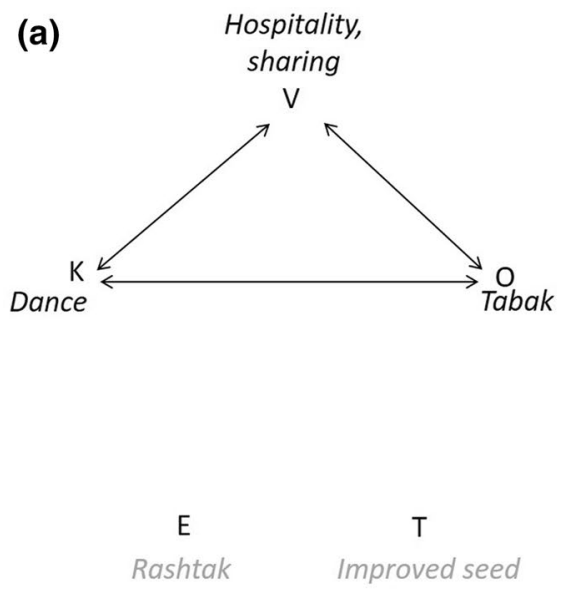

Fig. 3 Coevolutionary representations of Village B. a The continued importance of a collective system of sharing and work and the value of hospitality, maintained as repositories of social-ecological memory in the harvest dance and Taomhoi meli (national foods day) presented also in Table 1. b An alternative coevolutionary configura-

previous social relationships which continue to coevolve (K-V-O), but in separation from the ecological aspects of the system. This is not to say that social-ecological relationships have become disconnected, but rather that the introduction of the new seed may have influenced a shift in values (Fig. 3b). Given that the improved seed varieties failed after only 2 years, the technology (the seed itself) disappeared, but an alternative value system continued to be shaped long after the seed stopped being planted (Fig. 3b). The improved seed disappeared (T), but the relations that had co-evolved with this technology remained. Many other factors, such as the availability of cheap flour from shops, set in motion an alternative pathway of development.

\section{Discussion}

We set out to understand the effects of development interventions on the coevolution of biocultural landscapes, as expressed through changes in daily practice and ritual and the cultural change that occurred in two Pamiri communities. The introduction of improved wheat seed varieties had deleterious effects on local landrace varieties, such as Rashtak. In the more remote Village A they kept the Rashtak seed, while in Village B, Rashtak and the entire practice of growing grains was lost. In both communities, the ritual of Baht-ayom continues, though in starkly different ways. The seeds are meant here only as representative of interventions in the region at the time. While the results are presented to purposefully juxtapose villages $\mathrm{A}$ and $\mathrm{B}$, the traditions that form the identities of the villages are far from static. (b)

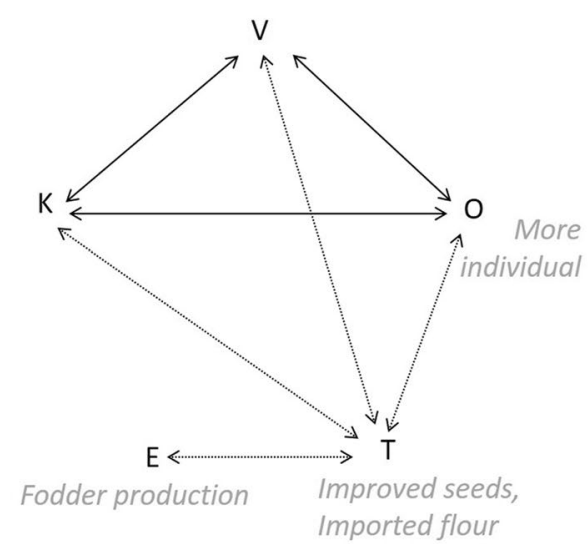

tion of Baht after the introduction of the improved Mahmoudi seed, with knowledge and values left open. Other factors such as market influences, changing freedom of geographical and social mobility and access to external influences would also play a large role

In the following, we present implications of our insights for this type of development intervention by: (i) considering how coevolutionary relationships have been reconfigured as a result of the intervention; (ii) reflecting on the role of daily practice and ritual in defining holistic and emanicaptory development pathways; and (iii) demonstrating how consideration of daily practices as mechanisms of coevolution can help inform development interventions in biocultural landscapes.

\section{Reconfiguration of coevolutionary relationships in development processes}

Humans and nature are inextricably linked (Folke 2006; Cooke et al. 2016) and everything is constantly coevolving with everything else. In some contexts, coevolutionary relationships are very direct and observable, like in Village A where agricultural biodiversity and cultural diversity directly maintain each other through the ritual of Baht. In other cases, the links have become less direct, such as in Village B, where the ritual continues to be practiced in isolation from the ecological reality. In this sense, coevolution is a non-normative concept describing processes of change. In the way we conceptualise coevolution in this paper, it is a process that includes selective forces, through for example climate change, and also deliberation and agency, in which individuals, communities or societies select which practices are maintained. Nevertheless, in its operationalisation, the framework has often been applied in a normative way assuming that if the five components (as described by Norgaard 1994) are tightly connected, they have more capacity to adapt, evolve and to be resilient to change. With 
regards to agricultural interventions in particular, Norgaard describes that the problems of predicting how the ecological and economic system will respond are specific to the particular technologies used, using swidden agriculture in the Amazon as an example of where coevolution has stopped (Norgaard, 1994, p. 111). As a framework, we do not use coevolution in a normative sense, and therefore coevolution is also unable to 'stop' as such, but rather evolution continues as before, but the 'co' is with different 'components' (even if we assume the components only exist in relation to each other at any given moment in time). The case of Village B shows what happens when relationships change (Fig. 3). In Village B two seemingly conflicting set of values and social organisation have emerged, and they may continue to (co)evolve in different ways (Fig. 3). The introduction of high-yielding improved marketable varieties of crops $(\mathrm{T})$ and related knowledges, values and organisation are in contrast to the traditional values of sharing and hospitality, and it remains to be seen whether these conflicting values can continue to coexist and indeed coevolve. An NGO official reflected on this issue of conflicting values in the Pamirs:

Sometimes with development we are damaging the good culture that was there, when we are pushing entrepreneurship etc. we are damaging people's minds. The GBAO [Gorno-Badakhshan Autonomous Oblast] I knew 30 or 40 years ago, it's not anymore those people, it's not the same. Before it was much much better. Now we started to lose the good ways of thinking, with business. It was not part of our culture, not part of our faith. Whether we like it, or not, there is no other way to survive (Interview N2).

The results of this paper show that modernist interventions can cause a disconnect in daily practices, values and ecosystems. From an international development perspective, the question is how to improve economic well-being without breaking apart the tightly connected relationships that have been central to the innovation and resilience of farmers over centuries. The example of the two villages indicates that focusing on rituals can help reveal and strengthen social-ecological relationships that are important for maintaining biocultural diversity. Knowledge of the processes that maintain these relationships can help identify interventions that conserve biocultural diversity while at the same time enabling poverty alleviation. The role of ritual in defining alternative pathways is further explored in the following section.

\section{Role of ritual in development}

Our results offer insight into the role of practice and ritual in defining alternative development pathways, both in making changes in past and current social-ecological relationships explicit, and by providing an emancipatory space for novel pathways to emerge. The ritual of Baht shows how successful practices (selection of an early-ripening wheat seed) led to adaptive responses (a nutritious meal being prepared for new year in March when food stores are low), and how the celebration of Baht-ayom maintains collective values and knowledge, and self-organisation around tabaks. In the case presented in this paper, rituals embody the practices and knowledges that contribute to sustainable landscape management. The living (continuous) biocultural practices in Village A, and the harvest dance and Taomhoi meli celebration in Village B are manifestations of social and ecological memory (Barthel et al. 2010). The tacit knowledge that is passed on across generations through the sowing and harvesting of Rashtak and the skills to prepare Baht are examples of this memory. In Village A the value of Baht-ayom is rather obvious, as it maintains Rashtak, which grows in micro-climates where few other seeds grow, and ripens early and plays an important role in contributing towards local food security and nutritional diversity. In Village B however, the ritual of Baht-ayom has a less obvious function, as it retains a system of values, knowledge and social organisation that is no longer in line with the ecological dynamics. The intention however, is not to reduce ritual to its functional or adaptive role (Rappaport 1999, p. 2). Ritual has long been recognised as a carrier of social and ecological memory in natural resource management practices (Lansing and Kremer 1993; Scarborough 1998), and Baht provides an example of ritual as repository for this social-ecological memory, defined as accumulated experience and history of ecosystem management collectively held by a community in a social-ecological system has been described as a source of resilience (Barthel et al. 2010; Nykvist and von Heland 2014).

Yet, while the strategy for livelihoods has changed in the past 25 years in Village B, the knowledge of how to grow Rashtak and other grains may become important again in the future, since few other grains grow in the unique biophysical conditions of Bartang valley. A young person from Village $\mathrm{B}$ (currently living in the capital city of GBAO and recently returned from Moscow) described: "I leave in order to come back" (Interview VB6). Indeed, Village B is full of half-built houses, to which young people plan to return once they have earned enough money to buy materials for the next part of the house. In the scenario that many young people return to Village $\mathrm{B}$, growing their own grain may again become necessary or desirable to restore the landscape to its previous state with similar ecological and cultural values. On the other side, rituals and the memory they store may become maladaptive and sources of inertia over time, prohibiting necessary change (Nykvist and von Heland 2014). Ritual can equally harbour unjust power relationships and exert control over marginalised groups within the local communities 
where they exist. Through using a coevolutionary framing we do not judge whether tradition and memory is good or bad but rather assess the role it plays in an on-going evolutionary process. A recent paper by Horcea-Milcu et al. (2017) proposes that a greater consideration of the coevolution of social-ecological systems with value systems can be an important step in helping to understand and manage change in highly valued, and threatened cultural landscapes. Ritual plays not only a role in adaptation to changing development challenges but also for the potential for transformative change in creating emancipatory pathways of change.

The practices that comprise the ritual of Baht-ayom reinforce tight reciprocal relationships between people in tabaks, and between people and landscape, creating a visible source of pride, agency and resistance. Ritual in other contexts has also been known to build social capital in the form of collective action and reciprocity (Olsson and Folke 2001). Hegland (1995, p. 69), writing about rituals in North West Pakistan, claims that "any action contains aspects of agency and resistance as well as control [...] and even within the confines of ritual people can find creative and agential opportunities." As was observed in Village A, traditional seeds were maintained in part because of their link to the ancestors, as one of the few artefacts passed down through the generations, and people were not willing to give up their traditional seeds in favour of the new introduced ones. Ritual thereby provides a source of pride and identity, and emboldens a certain level of resistance to external interventions.

\section{Social, cultural and ecological change processes and future development}

People in the Pamir region have been subject to immense social and environmental changes in the past decades following the collapse of the Soviet Union. Due to the importance of aid in the region (see reference to Hazina above), the paper focuses on and demonstrates unintended consequences of a specific (but widespread) development intervention: loss of local varieties and daily practice, resulting in broader cultural change processes. The level of education of young people is very high, plots of land are becoming smaller over generations, and traditional seed varieties are being lost, all in the context of a growing population. The Pamirs present a paradox: most people want to stay, but there are few job opportunties so young people mostly choose to migrate to Russia (overwhelmingly with the intention to return) (Interview B6). The painting in Fig. 4 presents this paradox. As part of a separate study, a visioning exercise was undertaken (including a representative from both Village A and Village B). At the forefront are people in traditional clothing, engaging in a greeting of mutual respect, representing hospitality and sharing. At the same time, we see improved roads and infrastructure, job opportunities created through factories,

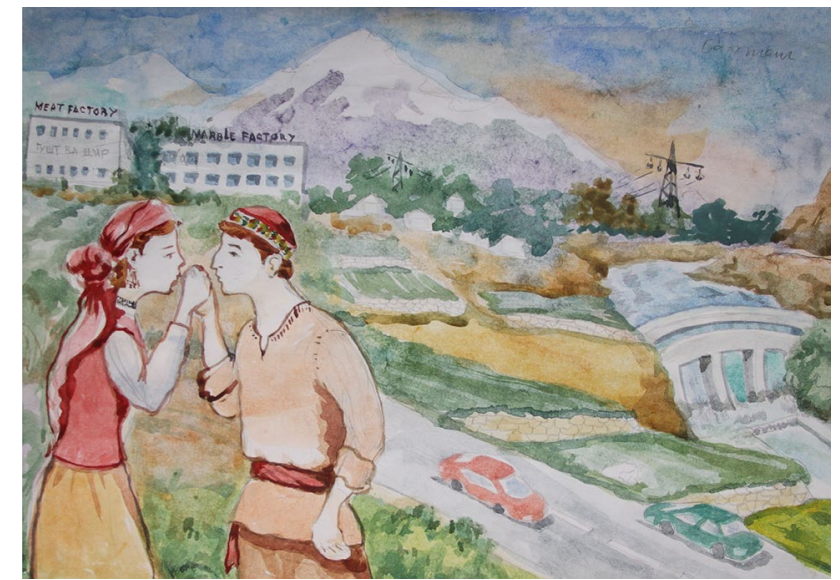

Fig. 4 Visions for a future of Bartang Valley, as imagined by representatives from Communities A and B (Artist: Yorali Berdov)

and energy provision through hydro power, and terracing to improve agricultural production. This provides some insight into the type of interventions communities appreciate, and also the values they wish to maintain.

Both Villages A and B offer hopeful experiences and visions in navigating past and future changes. In Village A, local grain varieties continue to be cultivated and biocultural practices maintained. Twenty-five years on from the specific intervention of Mahmoudi (though similar interventions are regularly introduced), ritual continues to play an important role in maintaining collective knowledge, values and organisation, despite ecological and technological changes. Our results suggest that continuous daily practice (sowing, harvesting celebrating) plays a role in maintaining social-ecological relationships and ability to continue living in Village A. In Village B however, the celebration of the ritual continues, but questions arise as to whether this ritual and the language, values and social organisation around it, will be maintained without the ecological reality (traditional seed varieties) and practices (sowing and harvesting) to support it. In this latter case the role of key knolwedge holders (such as the teacher of the harvest dance, and the school principal and librarian who host the annual traditional food celebration) become particularly apparent in maintaining biocultural knowledge through folklore.

The analysis of this past intervention surfaced insights and lessons learned which can be useful for informing future research and development interventions in the Pamir region-with which we now conclude. 


\section{Conclusions: re-thinking development interventions through the lens of ritual}

The results of this study are relevant in the context of recent development interventions in the Pamirs, and elsewhere, which seek to conserve biological as well as cultural diversity and heritage, while improving livelihoods (e.g. The Christensen Fund 2011). The paper offers two main contributions to re-thinking development processes to this end: (1) development interventions are part of a coevolutionary process, continuously changing relationships between society, environment, technology, values and social organisation, and (2) these relationships are manifested in daily practices and ritual, which provide an entry point for deeper understanding of past and future development trajectories or more appropriate intervention strategies.

The two villages in the case explored in this paper represent different configurations of social-ecological systems, where we analysed divergent responses as coevolutionary processes. The theoretical framing of coevolution can facilitate a more process-oriented and social-ecological approach to development. Understanding development processes as changes in coevolutionary relationships could help inform development interventions in mapping out important social-ecological relationships and their role or value in landscapes over time. Coevolution can thus clarify how social-ecolgical change can happen in different ways with divergent outcomes, providing useful guidance for development contexts where particular social-ecological relationships are valued. As such, a coevolutionary lens can provide a foundation for assessing intervention strategies: How to identify and maintain valuable relationships? And how to reconfigure restrictive relationships that create or maintain undesirable outcomes, such as persistent poverty or biodiversity loss? Fig. 4 offers some insight into the type of interventions that are desired in Bartang valley, and the types of relationships that wish to be maintained.

The coevolutionary approach also presented challenges when applied to empirical data. The motivation for using a coevolutionary approach was to focus on relationships as opposed to entities. The entities (nodes) represent snapshots in time of dynamic, constantly changing processes, and ritual provides the framing of a particular event to capture those given relationships. The ritual Baht represents spirituality, nutrition, health, agricultural biodiversity, fertility, and hospitality. Through Baht, we acknowledge interdependent relationships as opposed to disconnected component parts. When Pamiri people celebrate Baht-ayom, they celebrate past tidings and new beginnings; all of these 'components' are a part of baht. As scientists, we disembody the whole to make sense of the parts, only to recreate the whole again (O’Brien 2016). In practice, many development interventions are still binary in their focus, whether on poverty alleviation through high-input development interventions or conservation interventions (Roe and Elliott 2010).

Observing everyday practice and ritual overcomes limitations of binary conceptualisations of nature and culture through: (i) an explicit focus on the relationship between social and ecological, as opposed to their component parts, (ii) enabling a more holistic problem framing which incorporates all aspects of daily life, including health, spirituality, environment, access etc., and (iii) giving voice to ideas that are often marginalised or hidden within implicit or tacit knowledge. This paper shows how practice and ritual are a source of pride, and in this way provide a useful entry point to engage with a diversity of actors, since it gives voice to the most marginalised, who are involved in the everyday practices that create ritual. Using practice and ritual, particularly around food, can enable research and development practice to empower the people in landscapes who continue to actively create and care for it. The development goals in the Pamir region today aim to conserve biocultural heritage while improving human well-being. The insights from this paper suggest that focusing on daily practices and ritual as an entry point to research and development processes can make a valuable contribution towards more holistic and locally adapted development pathways.

Acknowledgements Open access funding provided by Stockholm University. The research was funded by the European Research Council under the European Union's Seventh Framework Programme (FP/2007-2013)/ERC Grant Agreement 283950 SES-LINK and a core grant to the Stockholm Resilience Centre by Mistra. We are grateful to the Mountain Societies Development Support Programme for their logistical support in the Pamirs. Most heartfelt thank-you to the two communities in Bartang valley for hosting us and sharing your knowledge. Thanks Emma Sundström for helping with the map. Thank you to Frederik van Oudenhoven for our many years of collaboration.

Funding European Research Council under the European Union's Seventh Framework Programme (FP/2007-2013)/ERC Grant Agreement 283950 SES-LINK and a core grant to the Stockholm Resilience Centre by Mistra.

\section{Compliance with ethical standards}

Conflict of interest The authors declare no conflict of interest.

Ethical approval All procedures performed in studies involving human participants were in accordance with the ethical standards of the institutional and/or national research committee (Stockholm Resilience Centre review, Stockholm University and in compliance with EU ethics guidelines) and with the 1964 Helsinki declaration and its later amendments or comparable ethical standards.

Informed consent Informed consent was obtained from all individual participants included in the study. Additional informed consent was obtained from all individual participants for whom identifying information is included in this article. 
Open Access This article is licensed under a Creative Commons Attribution 4.0 International License, which permits use, sharing, adaptation, distribution and reproduction in any medium or format, as long as you give appropriate credit to the original author(s) and the source, provide a link to the Creative Commons licence, and indicate if changes were made. The images or other third party material in this article are included in the article's Creative Commons licence, unless indicated otherwise in a credit line to the material. If material is not included in the article's Creative Commons licence and your intended use is not permitted by statutory regulation or exceeds the permitted use, you will need to obtain permission directly from the copyright holder. To view a copy of this licence, visit http://creativecommons.org/licenses/by/4.0/.

\section{References}

Acheson, J.M. 2006. Institutional failure in resource management. Annual Review of Anthropology 35 (1): 117-134.

Asia-Plus. 2014. Average monthly wage in Tajikistan stands at 820 somoni I Tajikistan News ASIA-Plus. Asia-Plus. https://www. news.tj/en/news/average-monthly-wage-tajikistan-stands-820-somoni. Accessed 15 Aug 2017.

Barthel, S., C. Crumley, and U. Svedin. 2013. Bio-cultural refugiaSafeguarding diversity of practices for food security and biodiversity. Global Environmental Change 23 (5): 1142-1152.

Barthel, S., C. Folke, and J. Colding. 2010. Social-ecological memory in urban gardens-Retaining the capacity for management of ecosystem services. Global Environmental Change 20 (2): 255-265.

Berkes, F., C. Folke, and J. Colding. 2002. Navigating social-ecological systems: Building resilience for complexity and change. Cambridge: Cambridge University Press.

Brown, K. 2016. Resilience, development and global change. Oxon: Routledge.

Chan, J., L. Pennisi, and C.A. Francis. 2016. Social-ecological refuges: Reconnecting in community gardens in Lincoln, Nebraska. Journal of Ethnobiology 36 (4): 842-860.

Cohen, B.P. 1989. Developing sociological knowledge: Theory and method. Chicago: Nelson-Hall.

Collins, R. 2004. Interaction ritual chains. Princeton, NJ: Princeton University Press.

Cooke, B., S. West, and W.J. Boonstra. 2016. Dwelling in the biosphere: Exploring an embodied human-environment connection in resilience thinking. Sustainability Science 11 (5): 831-843.

Danzer, A.M., B. Dietz, and K. Gatskova. 2013. Tajikistan Household Panel Survey: Migration, Remittances and the Labor Market. Survey report. Regensburg: Institute for East and Southeast European Studies.

Díaz, S., U. Pascual, M. Stenseke, B. Martín-López, R. Watson, et al. 2018. Assessing nature's contributions to people. Science 359 (6373): 270-272.

Fischer, K., and F. Hajdu. 2015. Does raising maize yields lead to poverty reduction? A case study of the massive food production programme in South Africa. Land Use Policy 46: 304-313.

Folke, C. 2006. Resilience: The emergence of a perspective for socialecological systems analyses. Global Environmental Change 16 (3): 253-267.

Folke, C., et al. 2016. Social-ecological resilience and biosphere-based sustainability science. Ecology and Society 21 (3): 41.

Haider, L.J., and F.J.W. Van Oudenhoven. 2018. Food as a daily art: Ideas for its use as a method in development practice. Ecology and Society 23 (3): 14.

Harmon, D. 2002. In light of our differences: How diversity in nature and culture makes us human. Washington, DC: Smithsonian Institution Press.
Hegland, M.E. 1995. Shi'a women of Northwest Pakistan and Agency through practice: Ritual, resistance, resilience. PoLAR 18 (2): $65-80$.

Ingold, T. 1993. The temporality of the landscape Tim Ingold. World Archaeology 25 (2): 152-174.

Jacobson, K. 2013. From betterment to Bt Maize Agricultural Development and the introduction of genetically modified maize to South African smallholders. Doctoral Thesis, Department of Urban and Rural Development. Swedish University of Agricultural Sciences, Uppsala, Sweden.

Kallis, G. 2007. When is it coevolution? Ecological Economics 62 (1): $1-6$.

Kassam, K.-A., U. Bulbulshoev, and M. Ruelle. 2011. Ecology of time: Calendar of the human body in the Pamir Mountains. Journal of Persianate Studies 4 (2): 146-170.

Kramer, D.B., et al. 2017. Top 40 questions in coupled human and natural systems (CHANS) research. Ecology and Society 22 (2): 44.

Kreutzmann, H. 2017. Oxford Research encyclopedia of Asian history historical geography of the Pamirs, 1-22. Oxford: Oxford University Press.

Lade, S.J., et al. 2017. Resilience offers escape from trapped thinking on poverty alleviation. Science Advances 3 (5): e1603043.

Lansing, J.S., and J.N. Kremer. 1993. Emergent properties of Balinese water temple networks: Coadaptation on a rugged. Source: American Anthropologist, New Series 95(1), 97-114.

Latour, B. 1993. We have never been modern. Cambridge, MA: Harvard University Press.

Lerman, Z., et al. 2003. Agricultural output and productivity in the former Soviet Republics. Economic Development and Cultural Change 51 (4): 999-1018.

Li, T. 2007. The will to improve: Governmentality, development, and the practice of politics. Durham: Duke University Press.

Lofland, J., and J. Lofland. 2006. Analyzing social settings: A guide to qualitative observation and analysis. Belmont: Wadsworth/ Thomson Learning.

Maffi, L. 2005. Linguistic, cultural, and biological diversity. Annual Review of Anthropology 34 (1): 599-617.

Mancilla Garcia, M., T. Hertz, and M. Schlüter. 2019. Towards a process epistemology for the analysis of social-ecological systems. Environmental Values. https://doi.org/10.3197/096327119X15579 936382608.

Markandya, A., and R. Sharma. 2004. Tajikistan: Reducing poverty through private infrastructure services-The Pamir Private Power Project Executive Summary. In Proceedings from scaling up poverty reduction: A global learning process and conference. Shanghai, May 25-27, 2004.

McAllister, P. 1992. Rural production, land use and development planning in Transkei: A critique of the Transkei agricultural development study. Journal of Contemporary African Studies 11 (2): 200-222.

Middleton, R. 2016. History of the development of the Pamir region of Tajikistan (Gorno-Badakhshan) 1. In Mapping transition in the Pamirs: With case studies on the changing human environmental landscapes, ed. Hermann Kreutzmann and Teiji Watanabe, 245-265. Cham: Springer.

Miles, M.B., and A.M. Huberman. 1994. Qualitative data analysis: An expanded sourcebook. Thousand Oaks: SAGE.

Mosse, D. 1998. Process-oriented approaches to development practice and social research. In Development as process: Concepts and methods for working with complexity, ed. D. Mosse, J. Farrington, and A. Rew, 3-30. London: Routledge Research/ODI.

Nabhan, G.P. 2009. Where our food comes from: Retracing Nikolay Vavilov's quest to end famine. Washington DC: Island Press/ Shearwater Books.

Norgaard, R.B. 1994. Development betrayed: The end of progress and a coevolutionary revisioning of the future. London: Routledge. 
Nykvist, B., and J. von Heland. 2014. Social-ecological memory as a source of general and specified resilience. Ecology and Society 19 (2): 47.

O’Brien, K.L. 2016. Climate change and social transformations: Is it time for a quantum leap? Wiley Interdisciplinary Reviews: Climate Change 7 (5): 618-626.

Olsson, P., and C. Folke. 2001. Local ecological knowledge and institutional dynamics for ecosystem management: A study of Lake Racken Watershed. Sweden. Ecosystems 4 (2): 85-104.

Peloquin, C., and F. Berkes. 2009. Local knowledge, subsistence harvests, and social-ecological complexity in James Bay. Human Ecology 37: 533-545.

Rappaport, R.A. 1999. Ritual and religion in the making of humanity. Cambridge: Cambridge University Press.

Raworth, K. 2017. Doughnut economics: Seven ways to think like a 21st-century economist. White River Junction, Vermont: Chelsea Green Publishing.

Reyes-García, V., et al. 2016. Multilevel processes and cultural adaptation: Examples from past and present small-scale societies. Ecology and Society 21 (4): 2.

Richerson, P.J., and R. Boyd. 2005. Not by genes alone: How culture transformed human evolution. Chicago: University of Chicago Press.

Robinson, S. 2005. Pastoralism in the Gorno-Badakhshan Region of Tajikistan. Nomadic Peoples 9 (1-2): 199.

Roe, D., and J. Elliott. 2010. The Earthscan reader in poverty and biodiversity conservation. London: Earthscan.

Sayer, A. 1997. Essentialism, social constructionism, and beyond. The Sociological Review 45 (3): 453-487.

Scarborough, V.L. 1998. Ecology and ritual: Water management and the Maya. Latin American Antiquity 9 (2): 135-159.

Scoones, I., and J. Thompson. 2011. The Politics of seed in Africa's Green Revolution: Alternative narratives and competing pathways. IDS Bulletin 42 (4): 1-23.

Scott, J. 1998. Seeing like a state: How certain schemes to improve the human condition have failed. New Haven: Yale University Press.

Slutskaya, N., A. Simpson, J. Hughes, et al. 2012. Lessons from photoelicitation: Encouraging working men to speak. Qualitative Research in Organizations and Management: An International Journal 7 (1): 16-33.

Smith, E.A. 2001. On the coevolution of cultural, linguistic, and biological diversity. In On biocultural diversity: Linking language, knowledge, and the environment, ed. L. Maffi, 95-117. Washington, DC: Smithsonian Institution Press.

Spradley, J.P. 1980. Participant observation. Long Grove, IL: Waveland Press.

Swedberg, R. 2017. Theorizing in sociological research: A new perspective, a new departure? Annual Review of Sociology 43 (1): 1-18. https://doi.org/10.1146/annurev-soc-060116-053604.

The Christensen Fund. 2011. Central Asia: First convening on agrobiodiversity and food sovereignty-Christensenfund. https:// www.christensenfund.org/2011/06/27/central-asia-first-conve ning-on-agrobiodiversity-and-food-sovereignty/. Accessed 16 Aug 2017.

Tidball, K., N. Frantzeskaki, and T. Elmqvist. 2016. Traps! An introduction to expanding thinking on persistent maladaptive states in pursuit of resilience. Sustainability Science 11 (6): 861-866.

Van Oudenhoven, F., and J. Haider. 2015. With our own hands: A celebration of food and life in the Pamir mountains of Afghanistan and Tajikistan. Utrecht: L.M. Publishers.

Vavilov, N.I. 1917. On the origin of cultivated rye. Bulletin of Applied Botany and Plant Breeding 10: 561-590.

Wanjala, B.M., and R. Muradian. 2013. Can big push interventions take small-scale farmers out of poverty? Insights from the Sauri Millennium Village in Kenya. World Development 45: 147-160.

West, S., et al. 2018. Stewardship, care and relational values. Current Opinion in Environmental Sustainability 35: 30-38.

Wiggins, S., and E. Cromwell. 1995. NGOs and seed provision to smallholders in developing countries. World Development 23 (3): 413-422.

World Bank, Migration and Remittances Team, D.P.G. 2014. Migration and remittances: Recent development and outlook. Washington, DC: World Bank.

Yin, R.K. 2003. Case study research: Design and methods, 3rd ed. Thousand Oaks, CA: Sage.

Publisher's Note Springer Nature remains neutral with regard to jurisdictional claims in published maps and institutional affiliations.

Jamila Haider is a post-doctoral researcher at the Stockholm Resilience Centre. She works on poverty, resilience, and development processes in food systems. She is co-author of a biocultural recipe book of the Pamir Mountains. She also studies inter- and trans-disciplinary research processes.

Wiebren J. Boonstra is an associate professor of Sociology at the Stockholm Resilience Centre. He has done research on farming and fishing styles, conflicts and power struggles over natural environments, technology and craftsmanship, and rural development in the global North and South. He also has a keen interest in the application of sociological theory in sustainability research.

Anzurat Akobirshoeva is a researcher at the Pamir Biological Institute of the Academy of Sciences of the Republic of Tajikistan. Her research expertise includes ethnobotany of medicinal and food plants as well as agrobiodiversity of rural mountainous areas.

Maja Schlüter is an associate professor at the Stockholm Resilience Centre. Her research focuses on analysing and explaining the co-evolutionary dynamics of social-ecological systems with the aim to develop social-ecological theory. 